\title{
Aviation MRO: Impact of Physical Environment Factors on Job Performance in Aircraft Maintenance Organization
}

\author{
Kamal Jaiswal ${ }^{1, *}$, Serdar Dalkilic ${ }^{1}$, Evangelos Papageorgiou ${ }^{1}$, Balgopal Singh $^{2}$ \\ ${ }^{1}$ Higher Colleges of Technology, Muroor Raod, Abu Dhabi, 25035, United Arab Emirates \\ ${ }^{2}$ Banasthali Vidyapith, Banathali, Distt.- Tonk, Rajasthank, 304022, India
}

\begin{tabular}{l} 
A R T I C L E I N F O \\
\hline Article history: \\
Received: 27 August, 2020 \\
Accepted: 11 October, \\
Online: 08 November, 2 \\
\hline Keywords: \\
Aircraft Maintenance \\
Physical environments \\
Job performance \\
Safety \\
Work Efficiency
\end{tabular}

\section{Introduction}

The human being is manipulating the environment for his survival and comfort contrary to the environment or nature is human's best friend and nearest surrounding. Unsafe and dangerous conditions may arise if we manipulate nature incorrectly and can make the life of human being very difficult. [1].

The efficiency of individuals and the work morale of individual at the workplace might get affected due to the hazardous environment resulting from the poorly administered surrounding. To determine the performance, morale and efficiency of an individual at a workplace, the workplace environment is a key factor. The workplace environment includes the area and condition in which an employee is executing the job however a positive and effective work environment is the

*Corresponding Author: Kamal Jaiswal, kamaljswl@gmail.com condition when the output of the individual working for an organization is same as expected as per job objective [2]. The physical environment where the job is being carried out by an individual significantly affect the performance of an individual.

The bodily atmosphere as a characteristic of the workplace atmosphere has an uninterrupted influence on human intelligence and can slowly variate interpersonal communications and therefore, efficiency. It happens because the features of space/room or an area have significance on the efficiency and happiness of individuals [3]. Several types of research have concluded that the features of a working area affect the satisfaction of the users. These features of a work area are preferred by the user and extremely important to the user for productivity and work satisfaction. These features include proper lighting, good ventilation, soundproofing, temperature and workspace etc. [4]. 
The factors like proper illumination of the workplace and suitable work resources such as furniture can have an encouraging effect on the health of an individual and subsequently on the efficiency. Other environment elements of a workplace such as controlled temperature, soundproofing, good ventilation etc. play a significant role in the productivity of an organization [5]. These elements ultimately influence the overall working atmosphere and decide the productivity and satisfaction.

The employees who are bodily and mentally motivated to do their job, the performance is expected to be enhanced, and safety is improved. A well-working environment can significantly reduce the absenteeism and conclusively enhance work efficiency [6]. The aircraft maintenance organization work under a complex system and the productivity of the individual decide the success of the organization. The efficiency of individual working in aircraft maintenance organization largely rely on working condition or physical working environment and it is the most important factor for safety as well [7]. The safety management system used in the aviation sector also address this issue and emphasize on providing a good physical environment to the individuals to perform the job safely. However, it is quite challenging for the management to provide a user-friendly environment to an individual in aircraft maintenance organization as the certain task to be performed on aircrafts requires an individual to work under adverse condition [8].

The output of an organization is directly linked with the satisfaction of employees with the physical environment of the workplace. The administration should regularly monitor and ensure that the physical working environment of the organization is conducive to work for the individual performing the job. The commitment of the administration to deal with work environment influences the motivation of the individual to perform properly and it should be assessed regularly and management should make necessary changes whenever required by employees to improve the efficiency and safety [9]. The changes may include, such as a change in the layout of the workplace or the addition of more resources.

Today's administration has to alter the way of working in order to get real modifications in these facets. The organization has to devote more time on governing these issues of the work situations rather than micromanage. This can be accomplished by enlightening on the physical workplace and amenities, assigning tasks, cumulative liability, and inspiring teamwork. This will encourage faith and devotion between the workers and boosts improved cooperation amongst them.

The capability of an employee to successfully perform a job in a tuff work environment is limited. The studies have revealed that a workspace feature changes the approach of employees and intensify their output. It also states that hazardous and insalubrious workplace atmosphere in terms of poor ventilation, incorrect illumination, disproportionate sound etc. disturb employees' efficiency and healthiness

\section{Physical Working Environment}

Aircraft maintenance engineers work inside a "complex system". There are plentiful characteristics inside this structure that encroach on the aircraft maintenance engineer, outspreading from his knowledge, skills and capabilities, the atmosphere in which he/she works, to the values of the organization for which he/she works. Even beyond the actual company employee works for, the governing requirements laid down for his/her job evidently impact on his/her comportment. All features of this structure may promote headed for inaccuracies that the engineer might make [10].

To well apprehend efficiency on jobs, it is vital to study the relationship between job performance, individuals, and circumstances elements. Job performance is a very substantial factor manipulating the cost-effectiveness of any organization. Performance is a key element for organizations as employees' performance directs to business success. Similarly, performance is vital for individuals, as accomplishing responsibilities can be a basis of happiness [2].

All the activity and behaviours that are executed by an individual, leading to attain the objectives of an organization can be termed as Job performance. The outcome of a task done by an individual or a group of individual in an organization on a specific time directly indicating that how well the individual or a group of the individual did that job while considering the organization's goal can be described as Performance. The physical environment such as operating conditions, procedures, resources and equipment to perform the job can majority impact the job performance of an employee [11].

In aviation, specifically in MROs, the job performance of an individual is very significant as the job performed by them is safety-critical. High level of job performance from an individual is required in the aviation industry to have a safe operation. The physical work environment and its impact have been enormously considered since the conditions can hamper, interfere with, or set restrictions on the variety of work behaviours that are exhibited which, in turn, possibly influences task performance [3].

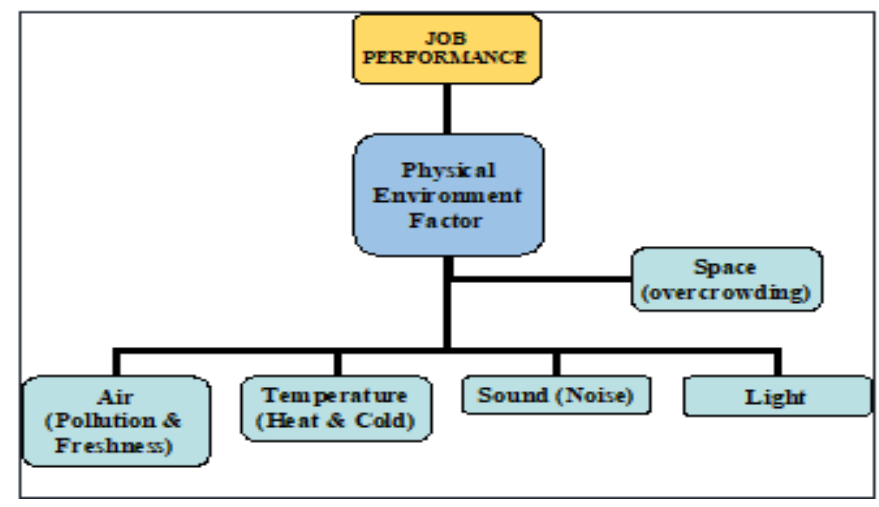

Figure 1: Physical Environment Factor

\section{Physical Environment Factor that Influences the Performance}

A vigorous interface is discovered between job performance and physical working environment, by the description of what is envisioned by the work environment and literature study findings [12]. The employees' performance, satisfaction, social relations and health is directly linked with physical environment of workplace. Generally, it is presumed that the bodily design of workstations and the ecological condition of workstation are 
substantial elements in organizational performance. The study of Badayai (2012) has established earlier studies and categorized five key aspects of an unpleasant working environment as shown in figure 1 .

\subsection{Air Factor}

The behaviour of individuals working in aircraft maintenance organization can significantly alter the job performance due to poor air quality resulting from lack of ventilation or any other factor. The quality of air significantly affect the health of individuals and describe the comfort level of the individual. Sometimes the quality of air can be very poor, specifically individual working with chemicals and in the confined area of aircraft in aircraft maintenance organization [5].

Utmost conceivably unsafe indoor air toxins are radon, asbestos, inorganic material, environmental tobacco smoke, organics, biological and non- ionizing radiation. Supplementary polluting agents such as odours and dust can be the source of serious uneasiness and feelings of reluctance that may lead to a fall in efficiency and job performance. A good ventilation system can overcome this issue and provide a sense of comfort with a combination of controlled temperature. Apart from this, some protective apparatus maybe use to avoid inhalation of pollutants in certain working conditions [10].

\subsection{Temperature}

The discomfort caused by temperature can be very painful and can significantly reduce job performance. Several types of research have established that the temperature of the workplace has a lot to do with how we interact with others in an organization. The behavior of individuals can significantly change when the temperature of the workplace is not conducive such as too hot or too cold [10]. Working under a condition either hot or cold can cause the lack of attention specifically in those tasks which require a great amount of focus such as crown inspection of rivets on aircraft or Non-destructive testing in workshops.

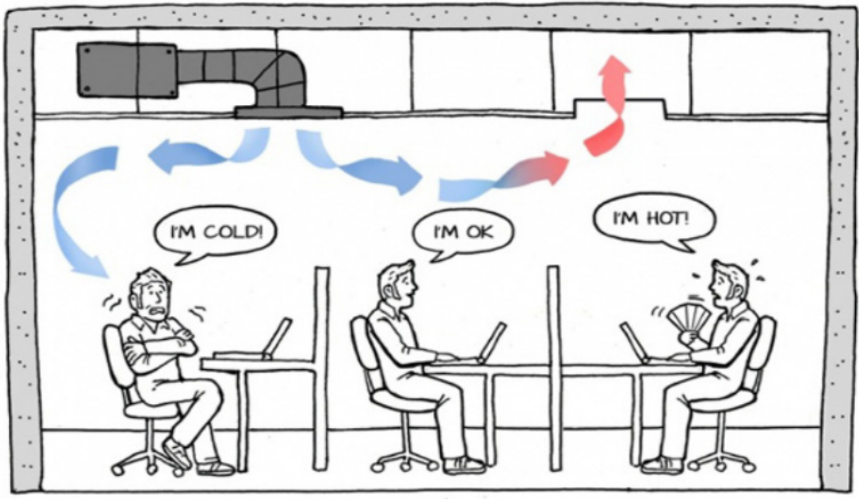

Figure 2: Effect of Temperature

A workplace, which is too hot or too cold, can be the source of stress and can affect the health of individuals. For example, Heat stress can make the body to drop electrolytes and $\mathrm{H} 2 \mathrm{O}$ quicker, triggering low psychological act and reduced motor skills. Your musculoskeletal system will be making efforts to save energy, which will absolutely slow your minds, making finishing tasks and escaping errors a hard accomplishment [4].

\subsection{Sound (Noise)}

Sound is amongst the substantial environmental factors for people's well-being, and it has a vital part in both physical and mental injuries, and it also disturbs individuals' performance and efficiency [6]. The aircraft maintenance engineering is frequently exposed to high noise level such as noise coming from Turbine Engine of the aircraft or from pneumatic equipment used by them. These high level of noise can significantly reduce the ability of an individual to perform efficiently and also have a serious impact on an individual's health both physical and mental [9].

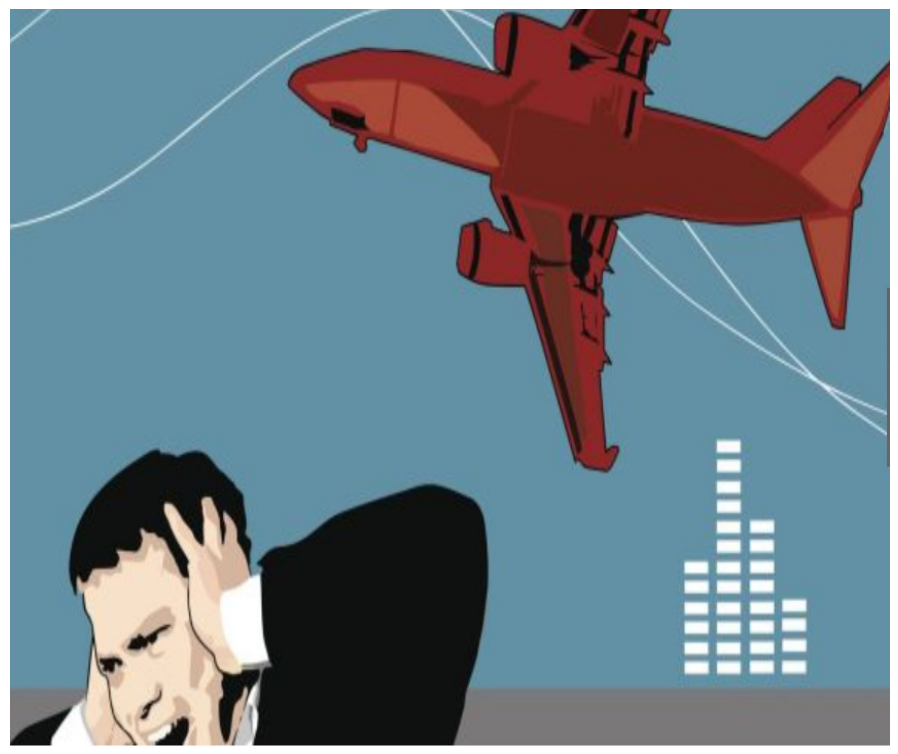

Figure 3: Noise

\subsection{Illumination}

Poor illumination often gets unnoticed in the workplace, as we talk about mental health and well-being, and the focus is firmly on creating happier and healthier workplaces. But bad lighting is related to a range of ill-health effects, both physical and mental, such as eye strain, headaches, fatigue and also stress and anxiety in more high-pressured work environments [1]. This becomes more significant in terms of aircraft maintenance, as several tasks carried out by aircraft mechanics in aircraft maintenance organization require adequate lighting. The improper lighting can cause serious safety risk as some defects or faults on aircraft may get unnoticed due to lack of lights or bright lights [6].

\subsection{Workspace}

The individual performing particular task requires an adequate workspace to perform the job properly, however, sometimes it is a bit impossible to have sufficient workspace while performing aircraft maintenance such as $\mathrm{C}$ checks performed as a part of major maintenance require several teams of aircraft mechanics to work together [8]. Having a confined space to work, affect the ability of an individual to perform the job and the situation may become worse when it comes with other adverse condition such as noise, time pressure etc.Captions must be written in sentence case (e.g., Macroscopic appearance of the samples.). 


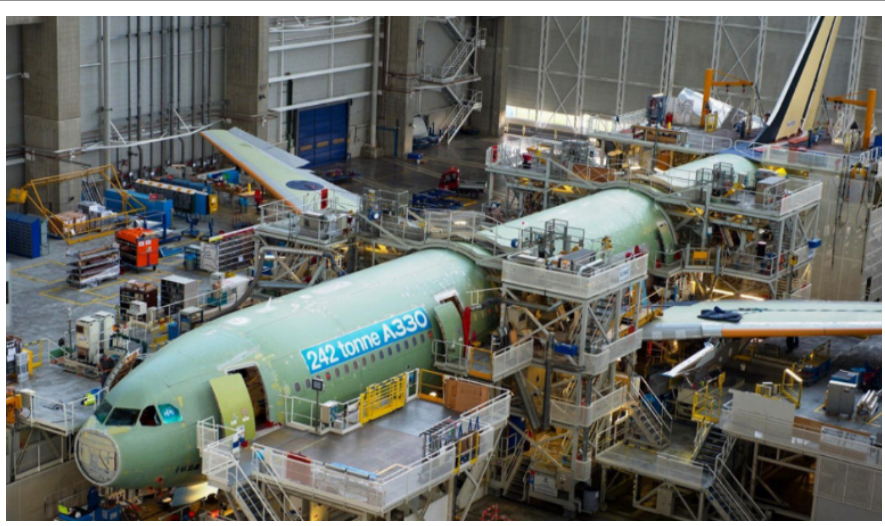

Figure 4: Workspace in MRO

\section{Research Methodology}

The objective of this research paper is to analyze the different physical environment factors disturbing work performance of individuals employed in the Maintenance Repair Overhaul (MRO) organization in the United Arab Emirates (UAE). The profile of intended respondent for this research is individual working in MRO inside the UAE and doing in maintenance activities such as aircraft maintenance technicians, aircraft maintenance engineers and other secondary staff. UAE is a key centre of aviation and patently has the finest airlines in the world. UAE also has the top capability for maintenance of aircraft in the region and unquestionably is the hub of premium MROs in the world. The MROs are functioning under a very multifaceted structure and use innovative technologies for daily operations. The agenda of the research was discussed with the intended audience to have an impartial examination of research elements.

Qualitative and quantitative approaches were engaged in measuring the physical environment factors. The research data was collected through paper-based surveys after a comprehensive conversation with individuals working in aviation MROs. The intended audience considered for this research were the employees of aircraft maintenance organization employed at a diverse level. This research was conducted as a part of the student's project and as project students have to go out and meet industry professionals in different aviation organization. The student involved in the research were studying a four-year Bachelor's Degree program in Aircraft Maintenance Engineering Major.

The structured questionnaire was used and the selection of questions was based on different elements of physical environment factors causing the problem at the workplace. The questionnaire includes the physical environment elements, which can possibly cause problems at the workplace, were related to:

- Inadequate lighting

- Noise

- Excessive Heat

- Excessive Cold

- Overcrowding

- Ventilation

- Fumes

- Maintenance equipment
Cronbach's alpha is used to test the reliability and validity. The Cronbach's alpha value is more than 0.70. The Cronbach's alpha of the questionnaire found to be 0.76 . The statistical method used to investigate the data is the frequency and percentage analysis. The data was collected using online survey platform survey monkey. The MS excel software was used to carry out the statistical analysis. The outcomes of the study were arranged after carrying out an in-depth examination of the data collected concerning physical environment elements affecting job performance. Table I shows the statistics of the research survey.

Table 1: Sample Table

\begin{tabular}{|c|l|l|}
\hline \multicolumn{3}{|l|}{ STATISTICS OF THE RESEARCH SURVEY } \\
\hline \multirow{2}{*}{$\#$} & Research Material & Quantity \\
\cline { 2 - 3 } & Type of Material & 22 \\
\hline 1 & Total questions included in questionnaire & 200 \\
\hline 2 & Total questionnaires distributed & $85 \%$ \\
\hline 3 & Percentage of responses received & \multicolumn{2}{l}{} \\
\hline
\end{tabular}

\section{Investigation Results}

The research outcomes are indicated in the form of the illustration, column and pie tables for the comfort of explanation. The percentage of replies is $85 \%$; it is good and imitates the individual's mindfulness and enthusiasm in relation to the physical environment of the organization.

Figure 5 shows that a total of 53\% of respondents NEVER had problems due to poor or inadequate lightings at the workplace. Total $38 \%$ of respondents choose that SOMETIMES they have problems due to improper lighting. Total $9 \%$ respondent OFTEN have problems caused by inadequate lighting at the workplace. In aviation, the adequate lighting is quite critical especially when individuals are working in complex and small aircraft parts during the night and in a dark atmosphere.

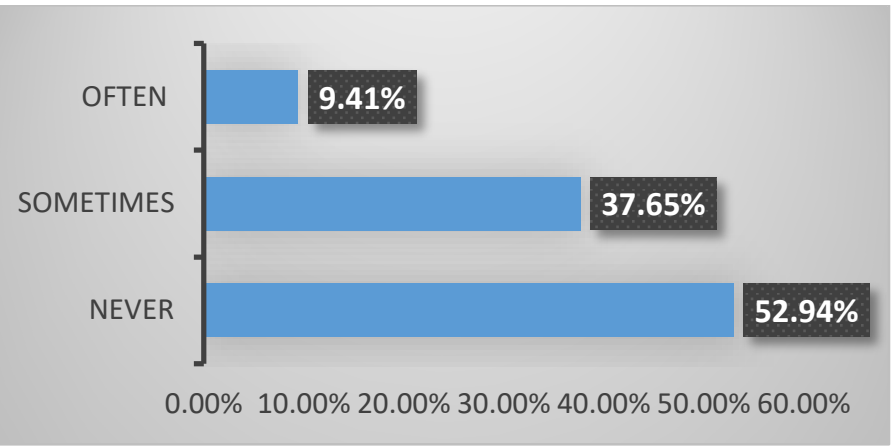

Figure 5: Poor/inadequate Lighting

Figure 6 shows frequency responses to the problem caused by noise at the workplace. As shown, $41 \%$ of respondents NEVER have a problem due to noise at the workplace, and $43 \%$ of them SOMETIMES have problems due to noise. However, $16 \%$ of respondent OFTEN have problems due to noise. Noise can be very annoying and can have a serious impact on health, which can lead to degradation of work performance

Figure 7 shows responses to the effectiveness of individuals exposed to excessive heat. As indicated in the figure, $49 \%$, respondent NEVER have excessive heat working condition, 39\% SOMETIMES have excessive heat working condition, and $11 \%$ 
respondent OFTEN have excessive heat working condition. This is a clear indication that working under excessive heat condition cannot be avoided, but it affects your performance and individuals get less effective when adverse conditions arise.

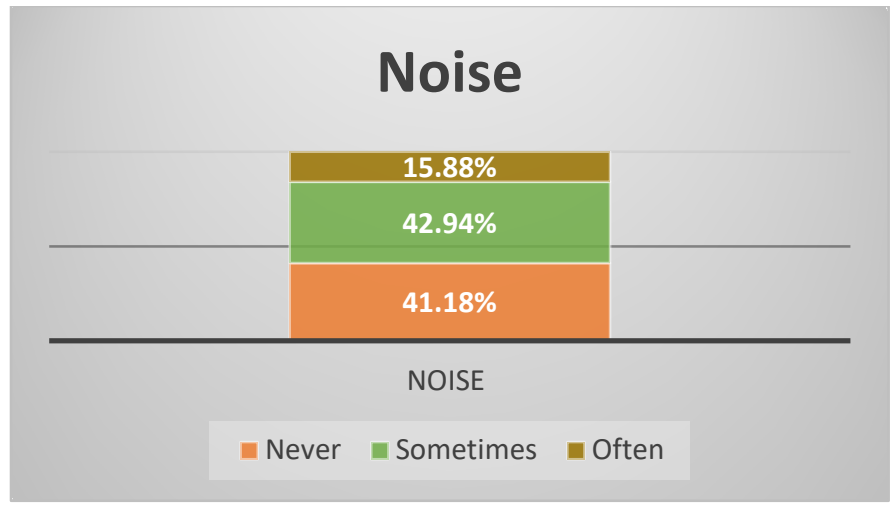

Figure 6: Noise

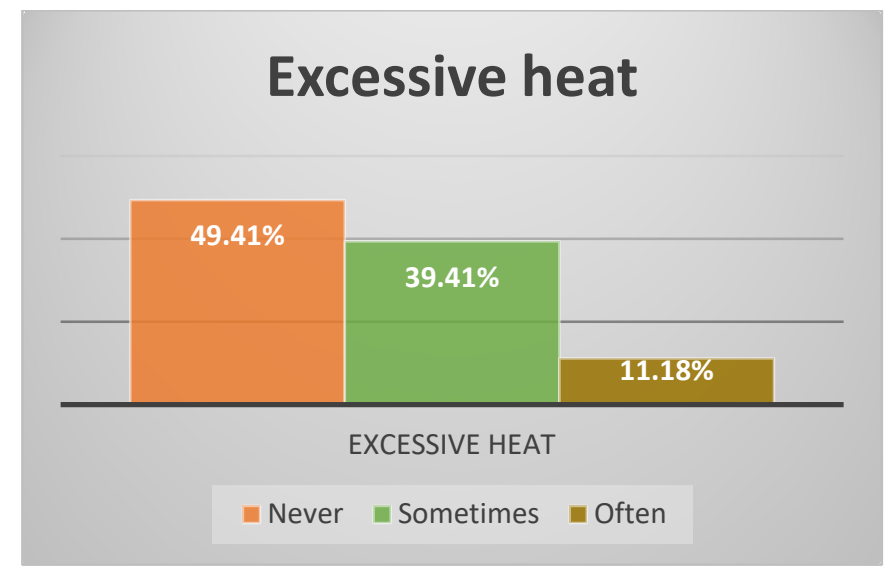

Figure 7: Excessive Heat

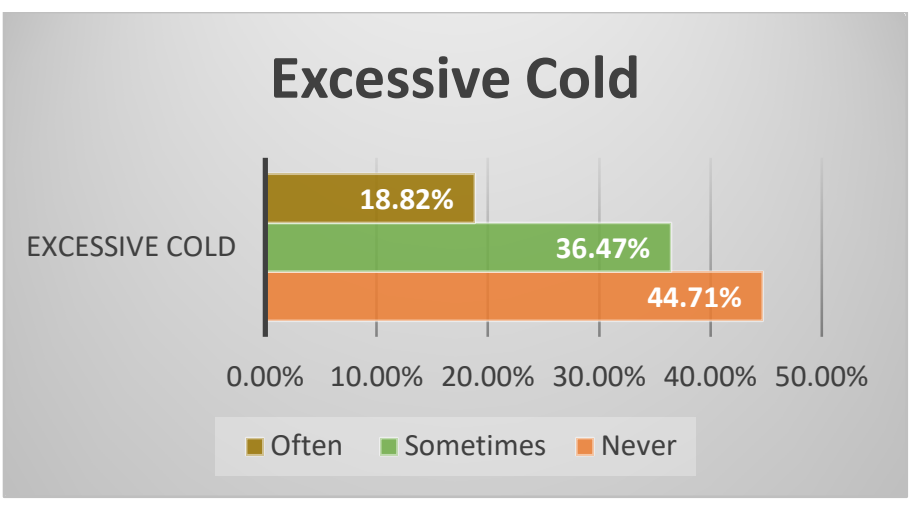

Figure 8: Excessive Cold

Figure 8 , shows that $45 \%$ of respondents have acknowledged that they NEVER a condition of excessive cold at the workplace while $36 \%$ of respondents SOMETIMES have the excessive cold condition at the workplace and almost $19 \%$ respondent OFTEN have the excessive cold condition at the workplace. These percentages seem to be quite significant and require action by the organization to control the physical environment condition of the workplace to make it more conducive.
Figure 9 shows responses to the overcrowding of the workplace leading to lack of workspace. About 45\%, 40\%, and $15 \%$ have responded to NEVER, SOMETIMES and OFTEN respectively. This result reflects that the majority of the people have an issue related to overcrowding of the workplace.

\section{Overcrowding}

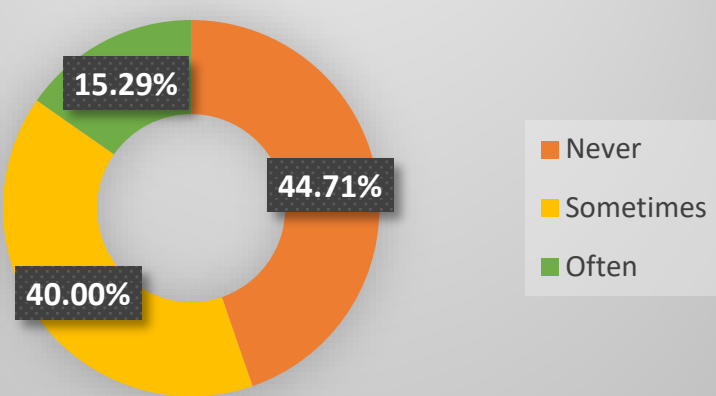

Figure 9: Overcrowding

Figure 10 shows responses to poor ventilation condition at the workplace. About 51\%, 38\% and 11\% have responded to NEVER, SOMETIMES and OFTEN respectively. These results reflect that ventilation condition needs some improvement and it becomes more significant when dealing with hazardous chemicals.

\section{POOR VENTILATION}

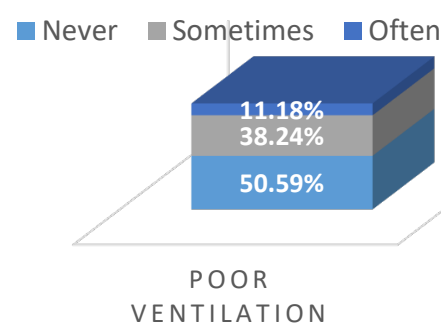

Figure 10: Poor Ventilation

Figure 11, shows responses to the question related to the presence of Dust and Fumes at the workplace. About 54\% of respondents NEVER have problems related to dust/fumes, 29\% respondent SOMETIMES have problems with dust/fumes and 16\% respondents OFTEN have problems with dust/fumes. It indicates that only small no. of the individual having a problem with dust or fumes and thus interfering with their work.

Figure 12, shows the results of poor maintenance condition of equipment used by individuals causing the problem at work. It was found that $52 \%$ of respondents NEVER have the problem of poor maintenance of equipment they use, 35\% respondent SOMETIMES have the problem of poor maintenance condition of the equipment they use and only $12 \%$ respondent OFTEN have the problem of poor maintenance of equipment they use. This 
matter is directly related the work performance as equipment used by an individual in the organization provides the basis of good maintenance of aircraft.

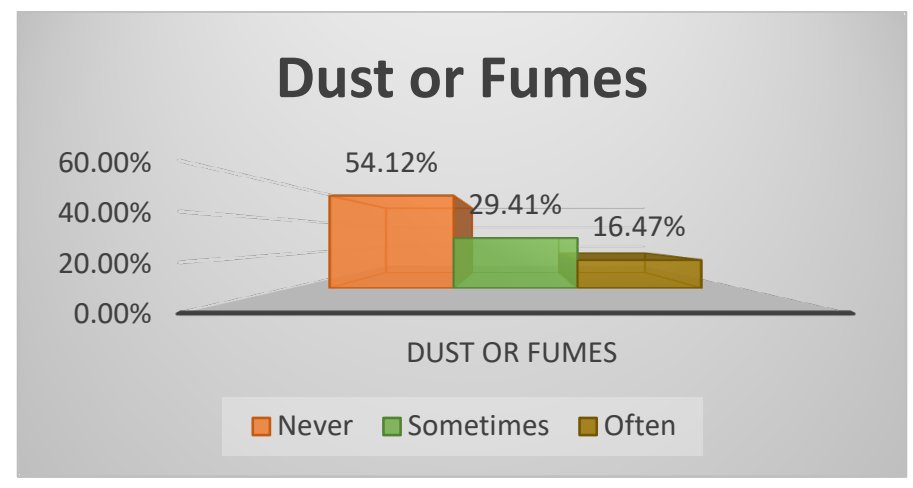

Figure 11: Dust or Fumes

\section{Poor Mainteannce of equipment}

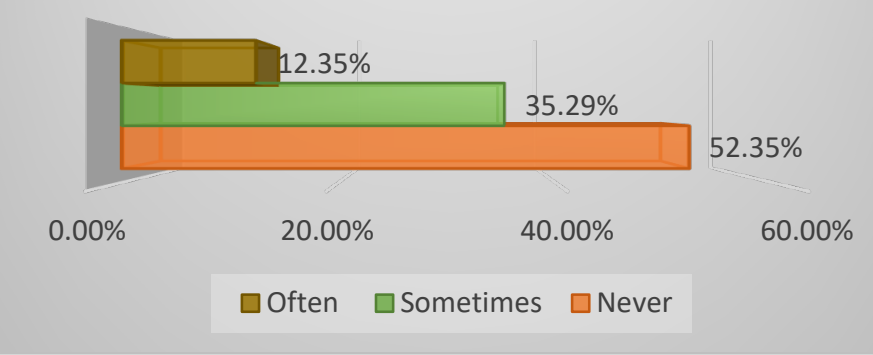

Figure 12: Poor Maintenance of Equipment

\section{Discussion and Recommendation}

This research specified that (reference to Figure 5) people working in MROs in the UAE typically does not have an issue related to poor illumination, and it does not affect their work. It is a optimistic signal that organizations are aware of this and have the necessary resources in place. However, a substantial number of individuals do have a problem with poor lighting sometimes which further need to be investigated why.

The study presented (a reference to Figure 6) that individuals working in aircraft maintenance organization frequently exposed to Noise, which should be the matter of concern for MROs as noise can seriously degrade the performance of individuals. It is also found (a reference to Figure 9) that a large number of individuals have problems with overcrowding leading to lack of workspace to perform the job specifically for the individuals working in base maintenance.

The analysis from Figure 10, evidently specifies that a great number of persons never have an issue due to poor ventilation which can reduce the air quality of the workplace. However, some respondent reported that they often have an issue with poor ventilation and this need to fix as poor ventilation lead to poor air quality and can result in a poor health condition of individual.
Figure 7 and Figure 8, clearly indicates that the majority the individuals does not have issues related to excessive heat or excessive cold condition. It reflects that temperature control of the workplace is properly maintained to provide a conducive atmosphere to individual working in MRO.

Exploration of figure 12 specifies that the most of the individuals working in MRO's at UAE does not have an issue related to poor maintenance of equipment's they use. However, a significant number of respondents have indicated that they sometimes or often have problems due to poor maintenance of equipment's.

The underneath mention fact specifies the zones of development as per the results of this study, and the succeeding recommendations are identified:

- Increasing attentiveness of the physical work environment and its optimistic effects on the organization and the individuals.

- Management taking proactive action to resolve the problem related to poor working conditions.

- Additional efforts are required to improve working conditions to guarantee enhanced work performance.

- Gathering more often with staff to improve their comfortability to report and to obtain opinion to lift the whole work performance.

Further, a study with hefty no. of the participant and a comprehensive questionnaire is suggested. The study can be very valuable if it is linked to statistics of MRO's worldwide.

\section{Discussion and Recommendation}

In this exploration, efficiency and significance of physical environment factors affecting work performance in MROs were examined. The MROs in UAE have delivered great backing throughout the course the research and research data was formed with support from MROs. It is concluded that MROs generally have very good physical environment. The MROs are taking all necessary action to provide a conducive atmosphere for employees. However, there are areas for improvement for a better physical environment including the improvement in terms of overcrowding leading to lack of workspace and the introduction of a robust system for proactive actions related to a physical environment.

\section{Acknowledgements}

The study was led by endless and unceasing backing from Higher Colleges of Technology (U.A.E.) and different MROs within the United Arab Emirates. The delicate and specialized support by Each Subject Matter Expert has educated me the finest research guidance, and I am appreciative for the generous support delivered by them.

\section{References}

[1] A.A. Shikdar, "Identification of ergonomic issues that affect workers in oilrigs in desert environment." International Journal of Occupational Safety and Ergonomics, 10: 169-177, 2002, doi.org/10.1080/10803548.2004.11076605

[2] F.O. Becker, "Workspace creating environments in organization." New York, N.Y. : Praeger, x, 225 p. : ill, 1981. 
[3] F. Becker "Improving organizational performance by exploiting workplace flexibility.” Journal of Faculty Management, 1: 154-162, 2002.

[4] C.C. Berger, HH Ehrsson, "Mental Imagery Changes Multisensory Perception." Current Biology, 23(14), 1367-1372, 2013, doi.org/10.1016/j.cub.2013.06.012.

[5] P.E. Mohr, J.J. Feldman, J.L. Dunbar, et al., "The societal costs of severe to profound hearing loss in the United States." Internationl Journal of Technology Assess. 2000.

[6] R.G. Geen, "Preferred stimulation levels in introverts and extroverts: Effects on arousal and performance." Journal Personality Social Psycholog, 46, 1303-1312, 1984.

[7] C.H. Friend, Aircraft maintenance management, Harlow: Longman scientific and technical, 1992.

[8] GCAA-U.A.E., Civil Aviation Requirement-145, 05 revision-01, GCAAU.A.E., February 2016.

[9] A. Kumar, P.K. Sinha, "Human Error Control in Railways." Jordan Journal of Mechanical and Industrial Engineering, 2, 183-190, 2008.

[10] S.A. Stansfeld, M.P. Matheson, "Noise pollution: non-auditory effects on health.” British Medical Bullettin., 68:243-257, 2003. doi.org/10.1093/bmb/ldg033

[11] K. Persson-Waye, R. Rylander, S. Benton, H.G. Leventhall, "Effects on performance and work quality due to low frequency ventilation noise." Journal of Sound Viberation.;205:467-474, 1997 doi.org/10.1006/jsvi.1997.1013

[12] W.W. Clark, B.A. Bohn, "Effect of noise in hearing." JAMA the Journal of the American Medical Association; 281(17),1658-1659, 1999. DOI: 10.1001/jama.281.17.1658 